\title{
Effect of 15-PGDH on the Proliferation and Migration of Human Gastric Cancer Cells
}

Yucui Shen ${ }^{1}$, Lihong Lou ${ }^{2}$, Yuexing Lai ${ }^{2}$, Yingying $\mathrm{Lu}^{2}$ and Dadao Jing ${ }^{2, *}$

${ }^{1}$ Department of Gastroenterology, Branch of Shanghai General Hospital, Shanghai, China

${ }^{2}$ Department of Geriatrics and Gastroenterology, Shanghai General Hospital, Shanghai Jiaotong University, Shanghai, China

\section{Abstract}

Objective: To investigate the effect of stable transfection with NAD+-linked 15-hydroxyprostaglandin dehydrogenase (15-PGDH) on the growth, proliferation and migration of gastric cancer cells.

Methods: The levels of 15-PGDH in four kinds of gastric cancer cells with different differentiation rates were compared by RT-PCR measurements, and the poorly differentiated gastric cancer cells SGC7901 were chose to perform follow-up experiments. SGC7901 cells were transfected with recombinant plasmid pcDNA3/15-PGDH and empty plasmid pcDNA3 as a control by using lipofectamine 2000. Cells with steady expression capability were sorted out by G418. RT-PCR and Western blot were used to confirm the transfection and expression of 15-PGDH in SGC7901 cells. MTT, cell scratch assay, soft-agar colony formation assays were used to determine the proliferation, migration and cell clone formation activities of SGC7901 with stable transfection of 15-PGDH. Flow cytometry assay was used to examine the effect of 15-PGDH on cell cycle and apoptosis. RT-PCR was used to analyze the levels of cell cycle-related genes (p53, p21 and p16) and apoptosis-related genes (Survivin, BCL-2 and Caspase3).

Results: Both recombinant plasmid pcDNA3/15-PGDH and empty vector plasmid pcDNA3 were successfully transfected into human gastric cancer SGC7901 cell line. Proliferation, migration and cell clone formation capabilities of pcDNA3/15-PGDH groups were significantly inhibited compared with other two control groups $(\mathrm{P}<0.05)$. Flow cytometry results demonstrated an increased fraction of sub-G1 phase and the increase of apoptotic cells for pcDNA3/15-PGDH groups compared with other two control groups $(\mathrm{P}<0.05)$. The levels of p16, p21 and p53 mRNA for pcDNA3/15-PGDH groups were higher than those in other two control groups $(\mathrm{p}<0.05)$. pcDNA3/15-PGDH groups exhibited a higher level of caspase 3 mRNA but lower levels of survivin and BCL-2 mRNA in SGC7901 cells compared with other two control groups $(\mathrm{P}<0.05)$.

Conclusion: The gene transfection of 15-PGDH has negative effects on the growth, proliferation and migration of gastric cancer SGC7901 cells by inducing apoptosis and cell cycle arrest.

\section{Introduction}

Gastric cancer is a commonly observed malignant tumor and the most common cause of cancer-related mortality worldwide. New approaches for the treatment of gastric cancer are needed. Prostaglandin E2 (PGE2) has a predominant function in promoting carcinogenesis and cancer progression, including tumor cell proliferation, invasion, immunosuppression and angiogenesis. PGE2 and other prostaglandins are rapidly degraded and largely inactivated by the initial oxidation of their 15(S)-hydroxyl group catalyzed by NAD+-linked 15-hydroxyprostaglandin dehydrogenase (15-PGDH) . 15-PGDH is a prostaglandin-degrading enzyme which is highly expressed in gastrointestinal tract, lung and prostate mucosa in humans and other mammals [1]. Recent studies have shown that the reduction or loss of 15-PGDH expression may lead to tumor progression. 15PGDH expression is significantly low in many malignant tumors such as colon cancer, non-small cell lung cancer, breast carcinoma, esophageal squamous cell carcinoma and adenocarcinoma, gastric cancer [2-8] and some precancerous lesions, such as atrophic gastritis [6]. 15-PGDH was significantly down regulated in H.pylori-infected gastric human tissues and it may be a useful marker and a potential therapeutic target in $H$. pylori-induced gastric carcinogenesis [7]. COXs are the rate-limiting enzymes in the overall synthesis of prostaglandins. Two isoforms of COX have been recognized. COX1 is expressed constitutively to carry out housekeeping functions, whereas COX-2, the rate-limiting enzyme in the synthesis of PGE2, is highly inducible by growth factors, proinflammatory cytokines, carcinogenic substances, tumor promoters and has been regarded as are necessary. 8498/2017/128

\section{Publication History:}

Received: February 17, 2017

Accepted: August 09, 2017

Published: August 11, 2017

Keywords:

15-PGDH, Proliferation, Migration, Gastric cancer, Transfection $\mathrm{Li}$ et al found downregulated 15-PGDH expression in human nonsmall cell lung cancer tissues and 15-PGDH and COX-2 reciprocally regulate cancer angiogenesis, which may affect the prognosis of patients with NSCLC [10]. Our previus studies showed that 15-PGDH inhibitors could promote the proliferation of human gastric cancer cells and COX-2 inhibitors could inhibit the growth of gastric cancer cells by promoting the expression of 15-PGDH [11-12]. Together, these studies suggest that reduction or loss of 15-PGDH expression may be an early event in tumorigenesis and may be closely related to the occurrence and development of tumors. Therefore, deeper studies on the effect of 15-PGDH on gastric cancer and related mechanisms

In this study, we constructed a SGC7901 cell line with stable expression of 15-PGDH gene and investigated the effect of 15-PGDH on the growth, proliferation and migration of gastric cancer, and we also examined the association of 15-PGDH with gastric cancer cell

"Corresponding Author: Dr. Dadao Jing, Department of Geriatrics and Gastroenterology, Shanghai General Hospital, Shanghai Jiaotong University, Shanghai, China, E-mail: zhuyuanmin@sina.com

Citation: Li L, Yang G, Zheng J, Kang C, Wang J, et al. (2017) Effect of 15PGDH on the Proliferation and Migration of Human Gastric Cancer Cells. Int J Gastroenterol Disord Ther 4: 128. doi: http://dx.doi.org/10.15344/2393-

Copyright: (c) $2017 \mathrm{Li}$ et al. This is an open-access article distributed under the terms of the Creative Commons Attribution License, which permits unrestricted use, distribution, and reproduction in any medium, provided the original author and source are credited. 
Citation: Li L, Yang G, Zheng J, Kang C, Wang J, et al. (2017) Effect of 15-PGDH on the Proliferation and Migration of Human Gastric Cancer Cells. Int J Gastroenterol Disord Ther 4: 128. doi: http://dx.doi.org/10.15344/2393-8498/2017/128

Page 2 of 7

apoptosis and cell cycle. The results will provide the necessary theoretical basis for future applications of 15-PGDH in the prevention and treatment of gastric cancer.

\section{Materials and Methods}

\section{Cell culture and stable transfections}

The pcDNA3/15-PGDH and pcDNA3 plasmids were obtained from Hsin-Hsiung Tai (Department of Pharmaceutical Sciences, College of Pharmacy, University of Kentucky). Human gastric carcinoma cell lines AGS, BGC823, SCG7901 and MGC803 (obtained from Shanghai Institute of Biochemistry and Cell Biology) were maintained in RPMI-1640 (Gibco, United States) medium supplemented with 10\% fetal calf serum, $100 \mathrm{U} / \mathrm{mL}$ penicillin and $100 \mu \mathrm{g} / \mathrm{mL}$ streptomycin in a $5 \% \mathrm{CO}_{2}$ atmosphere at $37^{\circ} \mathrm{C}$. All transfections were carried out using Lipofectamine 2000 (Invitrogen, Carlsbad, CA). Stable clones were generated by selection in complete culture medium containing $500 \mathrm{mg} / \mathrm{L}$ G418 (Gibco Corp, USA). Ten days later the concentration of G418 changed to $200 \mathrm{mg} / \mathrm{L}$ in order to maintain screening pressure. G418-resistant clones were visible approximately 2 weeks after the selection. Then the G418-resistant clones were picked up and cultured. After 4 weeks of cloning we got 2 cell lines with stable expression of pcDNA3/15-PGDH. Cells were divided into four groups: Blank, pcDNA3, pcDNA3/15-PGDH-1 and pcDNA3/15-PGDH-2.

\section{mRNA analysis by Real-time RT-PCR}

The $\beta$-actin gene was used as an internal reference. The 15-PGDH primers and probes were designed using the Primer Express 2.0 software and synthesized by the Shanghai Bioengineering Company. Total RNA was isolated from the cells using the TRIzol extraction kit according to the manufacturer's protocol. RT-PCR was performed according to the manufacturer's instructions (Bio-Rad, Richmond, $\mathrm{CA})$. The quantitative relative expression was calculated as the ratio of gene copies detected to the copies of $\beta$-actin. The experiments were performed independently in triplicate. The polymerase chain reaction primers sequences are listed in Table 1.

\section{Protein analysis by Western blot}

Cells were lysed and prepared for total protein extraction. The protein concentration was determined by the BCA method (KeyGEN, China), and $30 \mu \mathrm{g}$ of protein lysates were subjected to SDS-PAGE. The electrophoresed proteins were transferred to nitrocellulose membranes (Whatman, USA), which were blocked in $5 \%$ non-fat milk and incubated overnight at $4^{\circ} \mathrm{C}$ with diluted primary antibodies (1:200, Santa Cruz Corp, USA). Membranes were then incubated with HP-conjugated secondary antibody (1:2,500, Cayman, USA). After washing with PBST buffer (PBS containing 0.05\% Tween-20), the membranes were probed using ultra-enhanced chemiluminescence Western blotting detection reagents. $\beta$-actin was used as the internal reference.

\section{Cell toxicity and proliferation assay by MTT}

The experimental groups of cells in the logarithmic phase of growth were seeded in 96-well plates at a cell density of $1.0 \times 10^{4} /$ well. For three consecutive days, $20 \mu \mathrm{L}$ of MTT $(5 \mathrm{mg} / \mathrm{mL})$ were added to the corresponding well, and cells were incubated at $37^{\circ} \mathrm{C}$ for an additional $4 \mathrm{~h}$. The reaction was stopped by lysing the cells with $150 \mu \mathrm{L}$ of DMSO (Sigma-Aldrich Corp, USA), followed by low turbulence for $10 \mathrm{~min}$. Optical density was measured at $490 \mathrm{~nm}$. The experiments were performed independently three times.

\section{Cell migration assay by cell scratch assay}

Cell migration was examined using the cell scratch assay. SCG7901 cells were seeded in six-well plates in culture medium containing $10 \% \mathrm{FBS}$ to reach $90 \%$ confluence. After $4 \mathrm{~h}$ incubation in serumfree culture medium, pcDNA3 and pcDNA3/15-PGDH plasmids were added to transfect the cells. After $24 \mathrm{~h}$, the cell monolayer was wounded by scratching with a $200-\mu \mathrm{L}$ pipette tip. After rinsing three times with PBS, the cells were allowed to migrate into the scratched area. A computer-based microscopy imaging system was used to take photographs $(10 \times$ or $4 \times)$ in the same field at $0,24,48,72 \mathrm{~h}$, respectively. The Image-pro plus 6.0 software was used to assess the scratch-wound healing areas, and migration areas $\left(\right.$ Area $\left._{\mathrm{m}}\right)$ at each time point were calculated as follows: Area $_{\mathrm{m}}=\mathrm{Area}_{0}-$ Area $_{\text {timepoint }}$ The experiments were performed independently in at least triplicate.

\section{Cell clone formation by soft-agar colony formation assay}

A layer of agar containing $2 \mathrm{~mL}$ of $0.6 \%$ low melting agar dissolved in growth media was poured into wells of a six-well cell culture dish and allowed to set at $4^{\circ} \mathrm{C}$ for $5 \mathrm{~min}$. A second layer $(2 \mathrm{~mL})$ containing $0.4 \%$ low melting agar dissolved in growth medium containing cells $\left(1 \times 10^{3}\right.$ cells/well $)$ was placed on top of the first layer and allowed to set at $4^{\circ} \mathrm{C}$ for $10 \mathrm{~min}$. Each cell type was seeded in triplicate. Growth medium was added on top of the second layer, and the cells were incubated in a humidified incubator at $37^{\circ} \mathrm{C}$ for 14 days. The medium was changed twice per week. Two independent experiments were performed. At the end of the experiment, colonies were stained for $1 \mathrm{~h}$ with $0.005 \%$ crystal violet, and incubated with PBS overnight to remove excess crystal violet. The colonies were photographed, and colonies with a diameter of at least $100 \mu \mathrm{m}$ were counted. The mean number of colonies per well was calculated.

\begin{tabular}{|l|l|l|}
\hline Gene & forword & reserse \\
\hline 15 -PGDH & GCAGCCGGTTTATTGTGCTT & CCTGGACAAATGGCATTCAGT \\
\hline$\beta$-actin & CCATCATGAAGTGTGACGTGG & TCTGCATCCTGTCGGCAAT \\
\hline p16 & ACGCCCTAAGCGCACATTC & GGTTCTGCCATTTGCTAGCA \\
\hline $\mathrm{p} 21$ & AGCAGAGGAAGACCATGTGGA & AGAAGATCAGCCGGCGTTT \\
\hline p53 & AGAGCTGAATGAGGCCTTGGA & TGAGTCAGGCCCTTCTGTCTT \\
\hline Caspase3 & TGGCATTGAGACAGACAGTGG & GGCATACTGTTTCAGCATGGC \\
\hline survivin & CCAGCACCTGAAAGCTTCCT & GCCTCATTCACAACCCTTCC \\
\hline Bcl-2 & GGTGCCACCTGTGGTCCACCT & CCTCACTTGTGGCCCAGATAGG \\
\hline
\end{tabular}

Table 1: The primers sequences of the polymerase chain reaction. 
Citation: Li L, Yang G, Zheng J, Kang C, Wang J, et al. (2017) Effect of 15-PGDH on the Proliferation and Migration of Human Gastric Cancer Cells. Int J Gastroenterol Disord Ther 4: 128. doi: http://dx.doi.org/10.15344/2393-8498/2017/128

Page 3 of 7

Flow cytometry analysis of cell cycle progression

The cell cycle was analyzed by flow cytometry. Cells in the logarithmic phase of growth were harvested by trypsinization without EDTA, washed with PBS, and centrifuged at $2000 \mathrm{~g}$ for 5 min to remove the supernatant. The cells were resuspended in 500$\mu \mathrm{L}$ binding buffer. After mixing with $5-\mu \mathrm{L}$ Annexin V-EGFP, nuclei were stained with propidium iodide for $15 \mathrm{~min}$ and then examined in a FACSCalibur flow cytometer. The experiments were performed independently in quadruplicate.

\section{Flow cytometry analysis of cell apoptosis}

Cells were harvested and diluted with PBS twice. Then, $5 \mu \mathrm{L}$ of Annexin V-EGFP and $5 \mu \mathrm{L}$ of propidium iodide $(20 \mu \mathrm{g} / \mathrm{mL})$ were added to $100 \mu \mathrm{L}$ of cells. Upon incubation in the dark for $15 \mathrm{~min}$ at room temperature, samples were diluted with $400-\mu \mathrm{L}$ PBS. Flow cytometry was carried out using a FACS instrument, and the results were analyzed using software. The experiments were performed independently in triplicate.

\section{Statistical analysis}

The data are expressed as the mean \pm S.D. Statistical analysis was assessed by Student's $t$ test (between two groups) or StudentNewman-Keuls test (among three or more groups), with SPSS 17.0 software (Univariate Analysis of Variance). P-values less than 0.05 were considered significant.

\section{Results}

Selection of human gastric cancer cell line and identification of SCG7901 cells stably transfected with 15-PGDH plasmid

From Figure 1a, it could be found that 15-PGDH mRNA levels of measured four human gastric cancer cell lines: MGC803>AGS>
BGC823>SGC7901. Accordingly, we performed the following experiments using the SGC7901 cell line. To study the expression pattern of the 15-PGDH in SGC7901 cells, 15-PGDH mRNA and protein were quantified by real time RT-PCR and Western blot analysis. Two cell lines with stable expression of pcDNA3/15-PGDH were obtained. Cell experiments were divided into four groups: Blank, pcDNA3, pcDNA3/15-PGDH-1 and pcDNA3/15-PGDH-2. The 15-PGDH mRNA expression levels of blank group, pcDNA3 group, pcDNA3/15-PGDH-1 and pcDNA3/15-PGDH-2 group were $1.00 \pm 0.09,0.98 \pm 0.13,8.91 \pm 0.25$ and $9.10 \pm 0.21$, respectively (Figure 1b). The levels of 15-PGDH in pcDNA3/15-PGDH-1 and pcDNA3/15-PGDH-2 groups were remarkably higher than those in pcDNA3 and blank groups (Figure 1c).

\section{The effect of 15-PGDH on the proliferation, migration and colony formation ability of SCG7901 gastric cancer cells}

Compared with the blank and pcDNA3 groups, the cellular viability in pcDNA3/15-PGDH-1 and pcDNA3/15-PGDH-2 groups obviously decreased (the inhibition rate increased). This inhibitory effect could be observed after $24 \mathrm{hr}$ of treatment (inhibition ratio $48.72 \pm 3.1 \%$, $\mathrm{P}<0.05)$, and their inhibition ratios were closed at $24 \mathrm{hr}, 48 \mathrm{hr}$ and $72 \mathrm{hr}(47.56 \pm 4.2 \%$ and $53.72 \pm 5.0 \%, \mathrm{P}<0.05)$ (Figure 2a, blue bars). The densities of migration cells in pcDNA3, pcDNA3/15-PGDH-1, pcDNA3/15-PGDH-2 and blank groups were $79.84 \pm 14.21,21.32$ $\pm 5.24,22.46 \pm 5.98,98.69 \pm 16.05$ cells $/ \mathrm{mm} 2$, respectively $(\mathrm{p}<0.05$, Figure $2 \mathrm{~b}$ ). The number of migrated cells in the pcDNA3/15-PGDH transfection groups was remarkably lower compared with blank and pcDNA3 groups. Cell colony formation was inhibited significantly in the pcDNA3/15-PGDH-1 and pcDNA3/15-PGDH-2groups, compared to blank and pcDNA3 groups (55 \pm 5.29 and $65 \pm 10.26$ vs $293 \pm 10.07$ and $283 \pm 6.24,(p<0.05$, Figure $2 c)$.

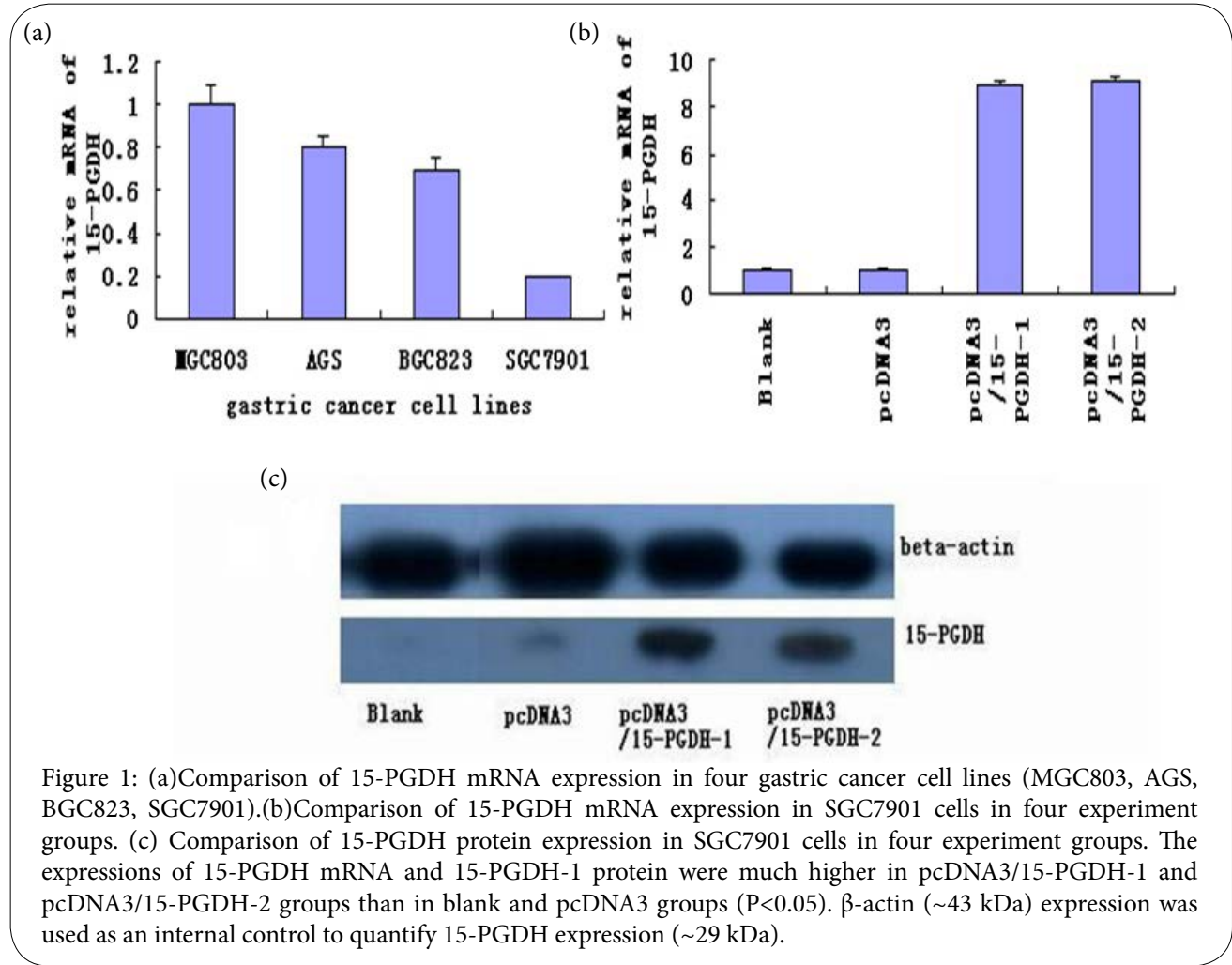


Citation: Li L, Yang G, Zheng J, Kang C, Wang J, et al. (2017) Effect of 15-PGDH on the Proliferation and Migration of Human Gastric Cancer Cells. Int J

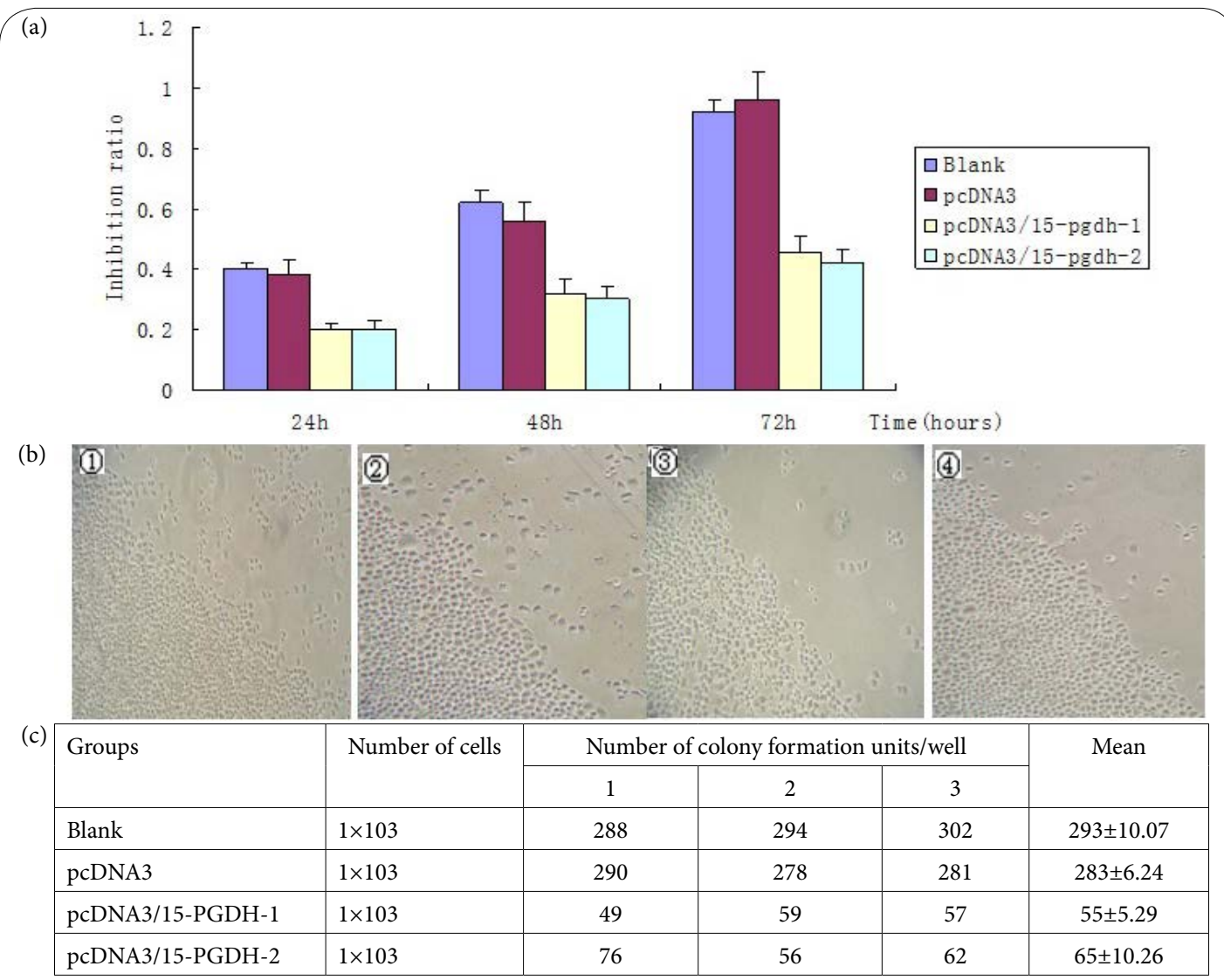

Figure 2: (a) The effect of 15-PGDH expression on the growth of gastric cancer cells (MTT method) (pcDNA3/15PGDH-1 and pcDNA3/15-PGDH-2 groups vs. other groups, $\mathrm{p}<0.05$ ). (b) The effect of 15-PGDH gene transfection on the migration of human gastric cancer SGC7901 cells (light micrographs). $\_,$, and represent blank, pcDNA3, pcDNA3/15-PGDH-1, pcDNA3/15-PGDH-2 groups with scratch-wounds at $48 \mathrm{~h}$, respectively $(\times 4)$. (c) The effect of 15 PGDH on the colony formation of SGC-7901 cells $(\mathrm{p}<0.05)$.

(a)
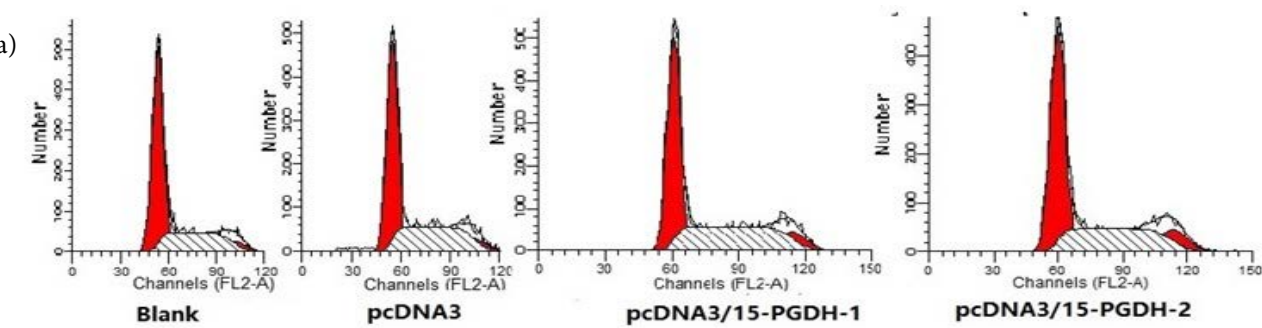

(b)

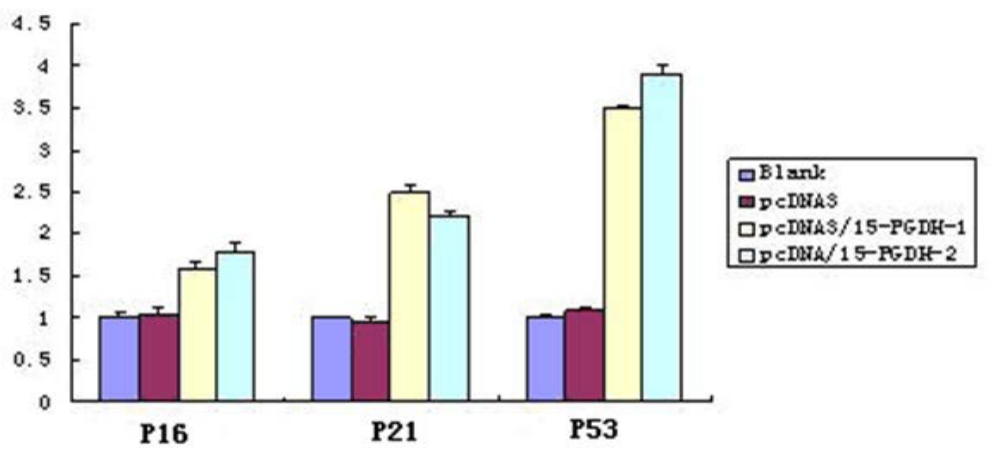

Figure 2: (a) The effect of 15-PGDH expression on the growth of gastric cancer cells (MTT method) (pcDNA3/15PGDH-1 and pcDNA3/15-PGDH-2 groups vs. other groups, $\mathrm{p}<0.05$ ). (b) The effect of 15-PGDH gene transfection on the migration of human gastric cancer SGC7901 cells (light micrographs). $\square, \square$, and represent blank, pcDNA3, pcDNA3/15-PGDH-1, pcDNA3/15-PGDH-2 groups with scratch-wounds at 48h, respectively $(\times 4)$. (c) The effect of 15-PGDH on the colony formation of SGC-7901 cells $(\mathrm{p}<0.05)$. 
Citation: Li L, Yang G, Zheng J, Kang C, Wang J, et al. (2017) Effect of 15-PGDH on the Proliferation and Migration of Human Gastric Cancer Cells. Int J Gastroenterol Disord Ther 4: 128. doi: http://dx.doi.org/10.15344/2393-8498/2017/128

The effect of 15-PGDH expression on the cell cycle of SCG7901 gastric cancer cells

Compared with pcDNA3 and blank groups, an effective transfection of 15-PGDH with pcDNA3/15-PGDH resulted in a significantly decreased proportion of SCG7901 cells in the $S$ and G2/M phases $(\mathrm{p}<0.05)$; however, the proportion of cells in the G0/G1 phase increased significantly ( $<00.05$, Figure $3 a)$. As shown in Figure $3 B$, the levels of p16 mRNA, p21 mRNA and p53 mRNA in the pcDNA3/15 PGDH- 1 and pcDNA3/15-PGDH-2 groups were higher than those in the blank and pcDNA3 groups $(\mathrm{p}<0.05)$.
The effect of 15-PGDH expression on the apoptosis of SCG7901 cells

15-PGDH induced the apoptosis of SCG7901 cells, as evaluated by flow cytometry (Figure 4a). The proportion of apoptotic cells in pcDNA3, pcDNA3/15-PGDH-1, pcDNA3/15-PGDH-2 and blank groups were $3.56 \% \pm 0.82 \%, 13.74 \% \pm 1.02 \%, 15.76 \% \pm 1.10 \%, 3.52 \%$ $\pm 0.88 \%$, respectively. The mean number of apoptotic SCG7901 cells in pcDNA3/15-PGDH-1 and pcDNA3/15-PGDH-2 groups were significantly higher compared to blank and pcDNA3 groups $(\mathrm{p}<0.05$, Figure $4 \mathrm{a})$. As shown in Figure $4 \mathrm{~b}$, caspase 3 mRNA in

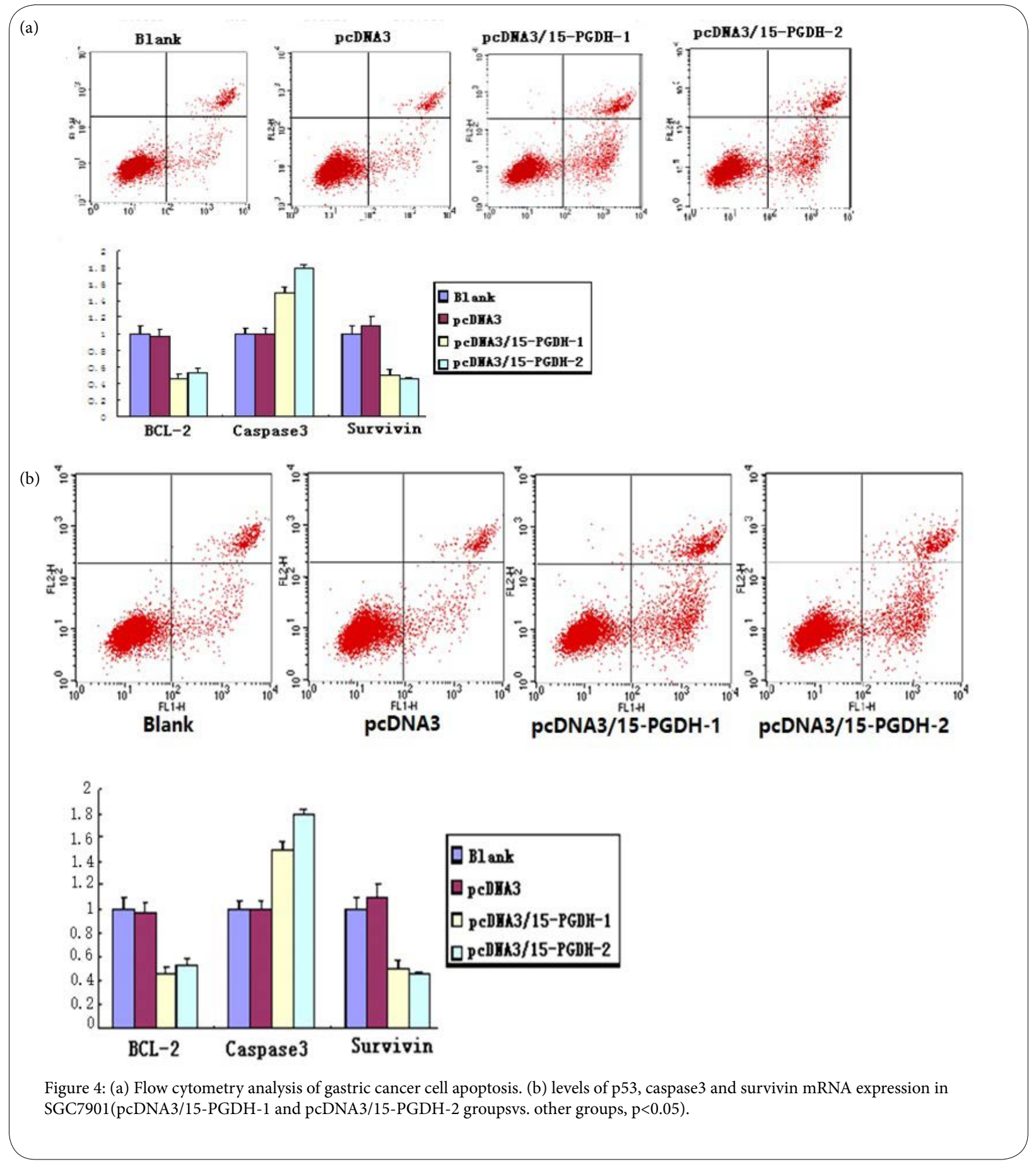


pcDNA3/15-PGDH-1 and pcDNA3/15-PGDH-2 groups was more than blank and pcDNA3 groups. BCL-2 and Survivin mRNA in the pcDNA3/15-PGDH-1 and pcDNA3/15-PGDH-2 groups were less than those in blank and $\mathrm{pcDNA3}$ groups $(\mathrm{p}<0.05$.

\section{Results}

15-PGDH, a prostaglandin-degrading enzyme, is a natural candidate as tumor suppressor. Previous studies have shown that 15PGDH functions as a potent inhibitor of carcinogenesis and that the expression of 15-PGDH is reduced or absent in a variety of malignant tumors, such as non-small cell lung cancer, breast cancer and prostate cancer. Our previous study showed that the expression of 15-PGDH was related to the degree of malignancy, TNM staging, distant metastasis and prognosis of gastric cancer. Lower expression level of 15-PGDH might lead to higher degree of malignant gastric cancer, suggesting that the reduced or lost expression of 15-PGDH indicates the presence of gastric cancer. In this study, we investigated the effect of 15-PGDH on the SGC7901 gastric cancer cell line, and our results clearly demonstrated that $15-\mathrm{PGDH}$ can effectively inhibit the cell growth, proliferation, and migration of SGC7901 cells. 15-PGDH also induced cell cycle arrest and apoptosis in SGC7901 cells. It may be a suppressor of gastric cancer through these pathways.

Yeon-Mi reported that 15-PGDH was significantly downregulated in $\mathrm{H}$. pylori-infected gastric human tissues, which suggested that 15-PGDH inhibition may be an early event in tumor carcinogenesis [7,13-15]. It had also been reported that reduction in the expression of 15-PGDH was associated with tumor differentiation [6], lymph node metastasis, clinical stage [16] and prognosis[17] in gastric cancer. In this study, we also found that the 15-PGDH expression was associated with gastric cancer cell differentiation, which was consistent with these previous reports. 15-PGDH mRNA was lower in poorly differentiated gastric cancer cell line than that in well differentiated gastric cancer cell line, and 15-PGDH mRNA decreased markedly in the poorly differentiated gastric cancer cell line SGC7901.

Some studies have demonstrated that 15-PGDH suppresses some tumors. The overexpression of 15-PGDH by transfection with plasmid or adenovirus vectors encoding 15-PGDH reduced the occurrence and growth of tumor[16,17], whereas the silencing of 15-PGDH using siRNA enhanced the proliferation and growth of cancer cells [16]. 15-PGDH gene knockout increased the colon tumor incidence in the $\mathrm{APC}+/ \mathrm{Min}$ mouse model [18].The restoration of 15-PGDH expression inhibited the proliferation of mouse murine forestomach carcinoma cancer cells[19]. However, the effect of 15$\mathrm{PGDH}$ on the growth and migration of human gastric cancer cell is not clear. In order to evaluate the effect of $15-\mathrm{PGDH}$ on the growth and migration of human gastric cancer cell, we established SGC7901 cell lines which were stably transfected with the 15-PGDH gene, and discovered significantly decreased proliferation of SGC7901 cells after being transfected with the 15-PGDH gene, which was consistent with the previous observation that 15-PGDH inhibited cancer cell proliferation $[19,20]$. The cell migration assay showed that 15-PGDH could inhibit the migration of SGC7901 cells. The soft-agar colony formation assay showed a smaller number of gastric cancer cell colonies after transfection with 15-PGDH compared to blank groups. These results suggested that $15-\mathrm{PGDH}$ played an important role in inhibiting the development, invasion and metastasis of gastric cancer, which further confirmed the close relationship between 15-PGDH and the development of gastric cancer [21-23].
$15 \mathrm{PGDH}$ is a gastric cancer suppressor, however, the related mechanism is not clear. Our previous study showed that 15-PGDH may induce the apoptosis of SGC-7901 gastric cancer cells and inhibit the cell cycle by transient transfection with 15-PGDH genes[6]. Can we get the same results if we stably transfect SGC7901 cells with 15PGDH gene? Here, we observed that gastric cancer cells could remain in the G0-G1 phase after being stably transfected with pcDNA3/15PGDH plasmids. Furthermore, we analyzed genes-associated cell cycle. There were increases in expression of p16, p21 and p53 genes which were known to regulate the tumor cell cycle [24-26]. We also found that the number of apoptotic SGC7901 cells after transfection with 15-PGDH was larger compared to those transfected with empty plasmid. There was a reduction in expression of antiapoptotic genes (BCL-2 and Survivin) but an increase in expression of proapoptotic genes (caspase3). Caspase is a key molecule of cell apoptosis and morphological changes of apoptosis is the results of a series of caspase activation and the hydrolysis of substrate, while the Caspase 3 is considered to be the main effector proteins. Ding found that When lung cancer cells A549 overexpress 15-PGDH by transfection with Ad-15-PGDH, they become apoptotic, as shown by DNA fragmentation, activation of procaspase- 3 and cleavage of poly ADP ribose polymerase[27]. Our results were consistent with the previous reports. Therefore, $15-\mathrm{PGDH}$ can block the cell cycle and inhibit gastric cancer cell growth. Upregulation of p16, p21 and p53 gene expression is a possible mechanism by which 15-PGDH makes gastric cancer cells to remain in the G0-G1 phase [28]. 15-PGDH also induced gastric cancer cell apoptosis BCL-2, caspase 3 and survivin genes may participate in this process [29-33].

In conclusion, our study provides evidences that the restoration of 15 PGDH expression inhibits the proliferation and migration of human gastric cancer cells, and 15-PGDH induces cell cycle arrest and apoptosis of gastric cancer cells in vitro, and it may be the mechanism by which it suppresses human gastric cancer. These results suggest that 15-PGDH plays an important role in inhibiting the growth, proliferation, migration and colony formation of gastric cancer cells and 15-PGDH may have potential as a novel and effective drug for the treatment of gastric cancer.

\section{Acknowledgments}

We thank Dr. Tai HH (Department of Pharmaceutical Sciences, College of Pharmacy, University of Kentucky, Lexington, United States) for donating 15-PGDH expression vector. We also thank Dr. Zhang QH (Shanghai Biochip Co., Ltd.) and his team for their expert technical assistance. The English in this document has been checked by at least two professional editors, both native speakers of English. So we thank them for checking our document.

\section{Funding}

This study was sponsored by Shanghai Science and Technology Commission Foundation (Grant No.06BZ066).

\section{Competing Interests}

The authors have declared that no competing interest exists.

\section{References}

1. Hansen SH (1976) 15-hydroxyprostaglandin dehydrogenase. A review. Prostaglandins 12: 647-679. 
Citation: Li L, Yang G, Zheng J, Kang C, Wang J, et al. (2017) Effect of 15-PGDH on the Proliferation and Migration of Human Gastric Cancer Cells. Int J Gastroenterol Disord Ther 4: 128. doi: http://dx.doi.org/10.15344/2393-8498/2017/128

2. Kang PS, Kim JH, Moon OI, Lim SC, Kim KJ (2012) Prognostic implication of 15-hydroxy- prostaglandin dehydrogenase down-regulation in patients with colorectal cancer. J Korean Soc Coloproctol 28: 253-258.

3. Hughes D, Otani T, Yang P, Newman RA, Yantiss RK, et al. (2008) NAD+dependent 15-hydroxyprostaglandin dehydrogenase regulates levels of bioactive lipids in non-small cell lung cancer. Cancer Prev Res 1: 241-249.

4. Celis JE, Gromov P, Cabezón T, Moreira JM, Friis E, et al. (2008) 15-prostaglandin dehydrogenase expression alone or in combination with ACSM1 defines a subgroup of the apocrine molecular subtype of breast carcinoma. Mol Cell Proteomics 7: 1795-1809.

5. Yang GT, Wang J, Xu TZ, Sun XF, Luan ZY (2015) Expression of PGDH correlates with cell growth in both esophageal squamous cell carcinoma and adenocarcinoma. Asian Pac J Cancer Prev 16: 997-1000.

6. Lou LH, Jing DD, Lai YX, Lu YY, Li JK, et al. (2012) 15-PGDH is reduced and induces apoptosis and cell cycle arrest in gastric carcinoma. World Gastroenterol 18: 1028-1037.

7. Ryu YM, Myung SJ, Park YS, Yang DH, Song HJ, et al. (2015) Inhibition of 15-Hydroxyprostaglandin Dehydrogenase by Helicobacter pylori in Human Gastric Carcinogenesis. Cancer Prev Res (Phila) 6: 349-359.

8. Song HJ, Myung SJ, Kim IW, Jeong JY, Park YS, et al. (2011) 15-hydroxyprostaglandin dehydrogenase is downregulated and exhibits tumor suppressor activity in gastric cancer. Cancer Invest 29: 257-265.

9. Tai HH (2011) Prostaglandin catabolic enzymes as tumor suppressors. Cancer Metastasis Rev 30: 409-417.

10. LiY,LiSL, SunD, Song L, LiuX (2014)Expression of 15-hydroxyprostaglandin dehydrogenase and cyclooxygenase-2 in non-small cell lung cancer Correlations with angiogenesis and prognosis. Oncol Lett 8: 1589-1594.

11. Lai YX, Jing DD, Lou LH, Lu Y (2012) Effect of 15-PGDH Inhibitor on Growth and COX-2 Expression in Human Gastric Cancer Cells. Chin Gastroenterol 17: 408-412.

12. Lai YX, Jing DD, Lou LH, Lu Y (2010) Effect of COX-2 Inhibitors on Growth of Gastric Cancer Cells and 15-PGDH Expression. Chin J Gastroenterol 15: $12-16$.

13. Tseng-Rogenski S, Gee J, Ignatoski KW, Kunju LP, Bucheit A, et al. (2010) Loss of 15-hydroxyprostaglandin dehydrogenase expression contributes to bladder cancer progression. Am J Pathol 176: 1462-1468.

14. Thiel A, Ganesan A, Mrena J, Junnila S, Nykänen A, et al. (2009) 15-hydroxyprostaglandin dehydrogenase is down-regulated in gastric cancer. Clin Cancer Res 15: 4572-4580.

15. Lee HJ, Yang DH, Ryu YM, Song M, Song HJ, et al. (2013) 15-hydroxyprostaglandin dehydrogenase in colorectal mucosa as a potential biomarker for predicting colorectal neoplasms. J Korean Med Sci 28: $1154-1160$

16. Tatsuwaki H, Tanigawa T, Watanabe T, Machida H, Okazaki H, et al. (2010) Reduction of 15-hydroxyprostaglandin dehydrogenase expression is an independent predictor of poor survival associated with enhanced cell proliferation in gastric adenocarcinoma. Cancer Sci 101: 550-558.

17. Liu Z, Wang X, Lu Y, Han S, Zhang F, et al. (2008) Expression of 15-PGDH is downregulated by COX-2 in gastric cancer. Carcinogenesis 29: 12191227.

18. Myung SJ, Rerko RM, Yan M, Platzer P, Guda K, et al. (2006) 15-Hydroxyprostaglandin dehydrogenase is an in vivo suppressor of colon tumorigenesis. Proc Natl Acad Sci USA 103: 12098-12102.

19. Li L, Yang F, Wang XJ, Hu J, Yang L, et al. (2014) Effect of 15-hydroxyprostaglandin dehydrogenase gene on the proliferation of gastric cancer cell murine forestomach carcinoma. Exp Ther Med 7: 290294.

20. Pham H, Eibl G, Vincenti $R$, Chong B, Tai HH, et al. (2006) 15-Hydroxyprostaglandin dehydrogenase is involved in anti-proliferative effect of non-steroidal anti-inflammatory drugs cox-1 inhibitors on a human medullary thyroid carcinoma cell line. Prostaglandins Other Lipid Mediat 81: 14-30.

21. Pham H, Eibl G, Vincenti R, Chong B, Tai HH, et al. (2008) 15-Hydroxyprostaglandin dehydrogenase suppresses K-RasV12dependent tumor formation in Nu/Nu mice. Mol Carcinog 47: 466-477.
22. Li M, Xie J, Cheng L, Chang B, Wang Y, et al. (2008) Suppression of invasive properties of colorectal carcinoma SW 480 cells by 15 -hydroxyprostaglandin dehydrogenase gene. Cancer Invest 26: 905-912.

23. Tatsuwaki H, Tanigawa T, Watanabe T, Machida H, Okazaki H, et al. (2010) Reduction of 15-hydroxyprostaglandin dehydrogenase expression is an independent predictor of poor survival associated with enhanced cell proliferation in gastric adenocarcinoma. Cancer Sci 101: 550-558.

24. Gayed BA, Youssef RF, Bagrodia A, Kapur P, Darwish OM, et al. (2013) Prognostic role of cell cycle and proliferative biomarkers in patients with clear cell renal cell carcinoma. J Urol 190: 1662-1667.

25. Zambirinis CP, Ochi A, Barilla R, Greco S, Deutsch M, et al. (2013) Induction of TRIF- or MYD88-dependent pathways perturbs cell cycle regulation in pancreatic cancer. Cell Cycle 12: 1153-1154.

26. Begnami MD, Fregnani JH, Nonogaki S, Soares FA (2010) Evaluation of cell cycle protein expression in gastric cancer: cyclin B1 expression and its prognostic implication. Hum Pathol 41: 1120-1127.

27. Ding Y, Tong M, Liu S, Moscow JA, Tai HH, et al. (2005) NAD+-linked 15-hydroxyprostaglandin dehydrogenase (15-PGDH) behaves as a tumor suppressor in lung cancer 26: 65-72.

28. Begnami MD, Fregnani JH, Brentani $\mathrm{H}$, et al. (2012) Identification of protein expression signatures in gastric carcinomas using clustering analysis. $J$ Gastroenterol Hepatol 27: 378-84.

29. Wall NR, O'Connor DS, Plescia J, Pommier Y, Altieri DC, et al. (2003) Suppression of survivin phosphorylation on Thr34 by flavopiridol enhances tumor cell apotosis. Cancer Res 63: 230-235.

30. Krstic M, Stojnev S, Jovanovic L, Marjanovic G, et al. (2013) KLF4 expression and apoptosis-related markers in gastric cancer. J BUON 18: 695-702.

31. Sun KW, Ma YY, Guan TP, et al. (2012) Oridonin induces apoptosis in gastric cancer through Apaf-1, cytochrome $c$ and caspase- 3 signaling pathway. World J Gastroenterol 18: 7166-7174.

32. Ghobrial IM, Witzig TE, Adjei AA (2005) Targeting apoptosis pathways in cancer therapy. CA Cancer J Clin 55: 178-194.

33. Hu M, Li K, Maskey N, Xu Z, Peng C, et al. (2015)15-PGDH expression as a predictive factor response to neoadjuvant chemotherapy in advanced gastriccancer. Int J Clin Exp Pathol 8: 6910-6918. 